\title{
Problems of mineral supplementation in modern farming systems
}

\author{
By D. Beaumont, BP Nutrition (UK) Ltd, Minsal Works, Wincham, Northwich, \\ Cheshire
}

A supplement manufacturer would find it easy to be persuaded that supplementation is a succession of problems which start when the supplement is designed and which does not necessarily end when the animal has excreted the fraction which it has not retained. Jaundiced as this view may be there are many real problems. In exploring some of them it may be that a picture of the industry will emerge; not always flattering and not how we would like.it to be but as it is today.

Before considering the animal at all a number of problems have to be recognized and some of these are consequences of the fact that mineral supplements are nearly always used as carriers of vitamins and trace elements. They may also be used as vehicles for growth promoters and other drugs. It is therefore necessary for the constituents in any supplement to be physically and chemically compatible and for the mixture to be stable for a reasonable length of time.

In general, one would say that the drugs present fewer problems than vitamins as far as stability is concerned. The hazards to vitamins are abrasion, moisture and trace element metals, particularly copper. Some abrasion is inevitable in the mixing process but fortunately most minerals contain little moisture with the exception of salt which is, of course, somewhat hygroscopic if exposed to moisture in the environment. With these thoughts in mind, packaging, careful transport and storage become important and few companies would willingly use very high levels of salt in a supplement containing fat soluble vitamins.

In the context of vitamin stability the effect of concentration has to be recognized. At one extreme we have supplements designed for inclusion at $2.5 \mathrm{~g} / \mathrm{kg}$ diet but others contribute the same levels of trace elements in upwards of $12.5 \mathrm{~g} / \mathrm{kg}$ diet. We find that we can guarantee vitamin stability of the larger inclusion products for twice the length of time that it is possible for the smaller inclusion.

Concentration can also be important if a high level of sulphates is called for. Historically pig supplements contributing up to $250 \mathrm{mg} \mathrm{Cu} / \mathrm{kg}$ finished food have caused most problems when an effort has been made to supply the $\mathrm{Cu}$ in a small volume of supplement. Such a supplement can solidify in a relatively short time to the extent that it becomes completely unusable.

The word 'guarantee' has been used already and it will serve as a reminder that since 1974 it has been mandatory to declare added vitamins $A, D$ and $E$ together with magnesium in excess of $5 \mathrm{~g} / \mathrm{kg}$ in the food, $\mathrm{Cu}$ in excess of $50 \mathrm{mg} / \mathrm{kg}$, molybdenum and selenium. Upper limits are fixed in some cases and limits of 
variation are prescribed. Supplements and compound foods must be labelled accordingly and vitamin potency guaranteed for a specific time. Further extension of statutory control is likely during $198 \mathrm{r}$. It appears that amongst other things a declaration of total ash will be necessary and this in itself raises some questions in relation to mineral supplements and one can foresee some controversy in the compound feed industry on this point.

This movement of supplementation into the legal sphere obviously means more quality control. This in turn means added costs which one suspects will eventually be passed on to the final user of the food. It is not suggested that quality control is unwelcome since reputable manufacturers have always sought confirmation that what was being supplied corresponded with what had been asked for and in fact my own company was monitoring incoming materials for arsenic, lead and fluorine long before these elements appeared on the list of 'undesirable substances' in the Fertiliser and Feeding Stuffs (Amendment) Regulations 1976.

Again, such monitoring costs money but quite apart from complying with legislation (little publicized and hardly enforced as it appears to be) it does give a manufacturer a firm base in ensuring that raw materials are up to specifications. It is then easier to control the finished product. This does not by any means absolve the company from quality control at the final stage. A strict sampling procedure together with a firm policy on rejection is essential and it has proved helpful on numerous occasions to retain reference samples as routine for at least 6 months.

Manufacturers also have a clear duty towards their staff which takes priority over products. This must be exercised when introducing any potentially toxic material into the mill. One might mention Se as a case in point where from the outside it might have appeared that there was undue hesitation in introducing this trace element into supplements. One had to consult the people concerned and develop procedures which were as safe as one could make them. The first step incidentally was to ensure that undiluted sodium selenite is handled only under closely controlled laboratory conditions and not in the manufacturing plant.

Again, from the outside the designing of a supplement might appear to be a simple matter. Basically, regardless of species, the questions to be answered are what supplements are needed, how much is required and how is it to be fed. Unfortunately the answers to these questions can make the issue far from simple.

Initially one should have a reasonably accurate idea of what is already in the diet. In the case of pigs and poultry where a single diet is normally fed at any one period in the life cycle it is relatively easy, since one has a good knowledge of the ingredients but unfortunately these can vary in composition quite widely. Purchase of material from a regular source is no guarantee of consistency and, as regards major minerals, animal proteins can introduce variability into the diet. Almost inevitably one is tempted to think of the average diet but in the supplement field and in the compound feed industry there are many who temper their calculations with a degree of pessimism in many respects.

The viewpoint that one should supply plenty of everything looks rather different when one considers possible adverse effects of over-supply and here some restraint 
is likely to be exercised so that the final diet may well supply rather less than the calculated quantity more often than not. Even with good quality control the supplement itself will not contribute minerals with absolute accuracy. There has to be a manufacturing tolerance.

This approach will not satisfy those to whom precision is paramount, but here one might well point out that there are disagreements between workers as to what mineral requirements are. Recommendations made by our Agricultural Research Council represent a concensus of opinion and it is possible to identify some differences between this authority and its counterpart in the USA. A perennial point of contention is whether or not these recommendations should be treated as requirements and what allowances should be made to make sure that they are met. One is tempted also to think of the average animal or bird and an average food intake. Most would accept that averages can be very misleading and cover everything from no intake at all to gross over consumption. Food intake is affected by climatic and other environmental factors as well as such factors as whether or not the stock is individually or group fed.

Supplementation for ruminants poses special difficulties in that with the possible exception of all concentrate diets for beef cattle there is relatively little control over much of the diet in terms of quantity and quality. Seasonal variations in grazed or conserved forages has to be accepted and the volume of work still being reported on factors relevant to forage intake is some indication of the uncertainties. The fact that we are putting materials into a fermentation system subject to its own vagaries as well as feeding an animal introduces more uncertainties. In these circumstances precision is hardly possible even if there is agreement as to what supplementation is needed.

How far should one go in catering for extremes? Should we be looking at mineral intakes more frequently in absolute terms rather than dietary concentrations? Clearly, decisions in this area too are not necessarily simple and eventually they must be coloured by commercial considerations. If costs of supplementation are low a generous allowance is more readily given. As examples one might quote calcium where $10 \mathrm{~g} \mathrm{Ca} / \mathrm{kg}$ diet would cost about $3.5 \mathrm{P}$ or $0.1 \mathrm{mg}$ $\mathrm{Se} / \mathrm{kg}$ diet which would cost less than Ip/tonne food. On the other hand more caution is likely to be exercised in the case of phosphorus where $\mathrm{I} g / \mathrm{kg}$ will cost at least $85 \mathrm{p} /$ tonne diet. These values are simple ingredient costs based on current prices and there are three observations to be made in this area.

First, whilst some of these costs might appear to be trivial they may well have to be multiplied by a value between 20 and 400 depending on the inclusion rate of the supplement and it is this value rather than cost/tonne which buyers will have in mind. Secondly, if one budgets for extreme situations it must mean that the majority will be presented with unnecessary costs. Thirdly, anyone involved in diet formulation will be aware that cost/unit weight of a supplementary mineral does not represent the complete picture. Mineral supplements take up space and this carries a specific cost which varies from diet to diet. In general one can say that where the aim is for high nutrient density the cost of mineral supplementation 
will be high since because of the space they take up one is compelled to use more concentrated and therefore expensive sources of energy and protein.

In this situation one is faced with a dilemma. A high-density diet is designed to give high animal performance on a small food intake and there is a case for increasing the level of supplementation. On the other hand there is pressure on space and from a cost/tonne point of view there is a temptation to reduce it. The eventual result is likely to be a compromise and indeed this is a word which can rightly be used very frequently in the field of mineral supplementation. In view of this it should not be too surprising to find that there are still problems in spite of supplementation and regrettably on some occasions because of it.

As a first example one might quote the danger of salt poisoning in whey fed pigs. The salt content of whey varies quite a lot depending on the type of cheese being produced. Whey intakes are generally high since the dry matter content is only $60 \mathrm{~g} / \mathrm{kg}$ diet or thereabouts and it is rare for an independent supply of fresh water to be provided. These pigs therefore are already close to difficulties in excreting excess sodium and there needs to be very little carelessness in the choice or usage of supplements to precipitate a dangerous and often fatal syndrome.

Human error can never be ignored as a possible source of problems. Omission is easy but as far as the pig is concerned the effects of omitting the major minerals are not immediate or dramatic. Some popular opinion suggests that there is an association of tail biting with low sodium diets but our own investigations have not supported this.

In the early days of the high $\mathrm{Cu}$ diets for pigs it was fashionable to use much higher levels of $\mathrm{Ca}$ than we do now. In view of what has since been learned of the interaction of $\mathrm{Ca}$ and zinc (and for that matter $\mathrm{Cu}, \mathrm{Zn}$ and iron) the prevalence of parakeratosis at that time is not surprising.

Without much doubt requirements of $\mathrm{Ca}$ and $\mathrm{P}$ for live-weight gain are less than those for maximum bone density. This has been reviewed by Partridge (1980). Bone fractures are highly undesirable from the point of view of both animal welfare and economics. Why risk them when the costs are so small? In case it is thought that fractures are never found in practice, a unit with about thirty pigs with broken limbs was investigated by the writer. The diet was unusual, based largely on waste foods and not supplemented at all.

It would be wrong to ignore possible differences in the $\mathrm{Ca}$ and $\mathrm{P}$ needs of boars compared with gilts and castrates in view of their rapid growth and high efficiency of food conversion. It would be wrong also to ignore possible effects of $\mathrm{Ca}$ and $\mathrm{P}$ on reproductive efficiency and the breeding lifespan of the sow. McRae et al. (1979) have indicated that there may be some connection and one wonders to what extent the incidence of posterior paralysis in sows might be due to skeletal demineralization.

The skeleton of the modern laying bird can serve regularly as a Ca reservoir but depletion will result in thin shelled eggs followed by cessation of lay or the birds going off their legs or both. Omission of supplementary $\mathrm{Ca}$ has caused these problems but it would be wrong to asssume that this is always so. Segregation of 
$\mathrm{Ca}$ due to its high specific gravity is a possibility if the mixed meal is being conveyed over a long distance. Some birds can receive consistently lower Ca diets than is desirable whilst others will receive a usually harmless excess.

Excess $P$ is known to have adverse effects on shell quality (Taylor, 1965). The usual source is animal proteins since it is in practice only rarely necessary to add phosphate as such to commercial layers' diets and unless care is taken these sources can readily provide excess. One would note that on occasion they have also contributed excess $\mathrm{Na}$.

Whilst one has seen a great deal of success in controlling wet droppings problems following the work of Mongin \& Sauveur (1977) this has not always been consistent simply because of changes in the diet without necessarily changing the formula. The same workers indicate that tibial dyschondroplasia may be connected with ionic imbalance and one wonders if this is at least part of the explanation of continuing leg problems particularly in turkeys. This species generally seems to be relatively sensitive to mineral problems.

In ruminants too there are problems because of supplementation. In dairy cattle Pickard (1977) demonstrated an association between pre partum feeding of supplementary $\mathrm{Ca}$ and $\mathrm{P}$ and the incidence of milk fever. This disease is almost certainly more common than it should be because of the reluctance of many farmers to take a special concentrate and the lack of interest by the trade in selling such a product.

Veterinary authorities often suggest that excessive $P$ levels lead to a high incidence of urolithiasis in intensively fed castrated lambs. Salt at up to $50 \mathrm{~g} / \mathrm{kg}$ concentrate has been suggested as a preventive measure (Anon, 1978).

Failure to take sufficient $\mathrm{Mg}$ is a common cause of tetany. Voluntary intake of fortified diet can be very variable in practice and one suspects that specific hunger can hardly be operating. Free access supplements are poor answers to this problem for this reason and because of excessive intakes by some individuals.

In the field of ruminant nutrition there is still a great deal of interest in mineral additives such as sodium bicarbonate and other materials which modify rumen function. Here one would like more information on the circumstances where an economic response is probable. Here again is some indication that we have a long way to go both in gathering new knowledge and making the best use of what we already have.

\section{REFERENCES}

Anon (1978). A. Rep. Dep. Agric. N Irl. p. 202.

Fertilizer and Feedingstuffs (Amendment) Regulations (1976). Statutory Instrument I976 No. 840. HM Stationery Office.

McRae, D. J., Handlin, D. L., Eargle, J. C. \& Johnston, W. E. (1979). Bull. Agric. exp. Stn, South Carolina 6rg.

Mongin, P. \& Sauveur, B. (1977). Growth and Poultry Meat Production [K. N. Boorman and B. J. Wilson, editors]. Edinburgh: British Poultry Science Ltd. 4, 235.

Partridge, I. G. (1980). Proc. Nutr. Soc. 39, 185.

Pickard, D. W. (1977). Nutrition and the Climatic Environment, p. II3 [Haresign, Swan and Lewis, editors]. London: Butterworths.

Taylor, T. G. (1965). Br. Poult. Sci. 6, 79.

\section{Printed in Great Britain}

